\title{
O cinema e a formação docente: um diálogo sobre as questões de gênero ${ }^{1}$
}

Vera Helena Ferraz de Siqueira

Doutora em Educação, pela Columbia University, e docente no Núcleo de Tecnologia Educacional para a Saúde/NUTES, da Universidade Federal do Rio de Janeiro/UFRJ.

E-mail:verahfs@yahoo.com.br

Cristiane Maia de Oliveira

Mestra em Tecnologia Educacional nas Ciências da Saúde pelo NUTES/UFRJ

(bolsista CAPES/MEC).

E-mail: cristianemaia@ig.com.br

Júlio Oliveira Braga

Bolsista de iniciação científica no NUTES/UFRJ, apoio PIBIC/SR2/UFRJ.

E-mail: juliobraga@nce.ufrj.br

$\mathrm{Na}$ formação docente, muitas vezes temáticas complexas como gênero e sexualidade são desconsideradas ou abordadas de forma unilateral e prescritiva, ignorando-se a dimensão essencial da subjetividade dos indivíduos. Do mesmo modo, também se descartam a importância dos meios de comunicação de massa e seu papel na constituição dos sujeitos - os papéis que assumem, seus valores e posicionamentos. Esses aspectos, entretanto, são de suma importância na prática docente, especialmente se lembrarmos que o currículo em ação é impregnado por questões com implicações diretas no exercício da sexualidade e na construção de identidades de gênero, que adentram a escola frequentemente através das mídias.

Maxine Greene ${ }^{2}$ observa que os papéis sexuais e de gênero assumidos pelas mulheres freqüentemente obscurecem sua percepção da realidade. A vida cotidiana é constituída por realidades interpretadas e homens e mulheres percebem suas experiências a partir de receitas disponíveis na cultura. Dessa forma, esses modelos servem como referencial para a atribuição de sentido às coisas e às relações entre seres humanos, tornando-se parâmetros para as mais diversas situações e experiências de vida.

1. Artigo baseado en pesquisa apoiada pela FAPERJ.

2. GREENE, M. The lived world (O mundo vivido). In: STONE, Lynda (Ed.). The Education Feminism Reader (Antologia de educação feminista). London: Routledge, 1994. 
3. HORKHEIMER, M.; ADORNO, T. W. O lluminismo como mistificação de massa. In: LIMA, Luiz Costa (Org.). Teoria da cultura de massa. Rio de Janeiro: Saga, 1969.

4. GEADA, E. O poder do cinema. Lisboa: Livros Horizonte, 1985

5. KELLNER, D. Lendo imagens criticamente: em direção a uma pedagogia pós-moderna. In: SILVA, Tomás Tadeu (Org.). Alienígenas na sala de aula. Petrópolis: Vozes 1995.

6. KAPLAN, E. A. A muIher e o cinema: os dois lados da câmera. Rio de Janeiro: Rocco, 1995.

7. GIROUX, H. Pulp Fiction and the culture of violence (Pulp Fiction e a cultura da violência). Harvard Educational Review, Harvard, v. 65, n. 2, p. 299-514, 1995.

8. DUARTE, R. Cinema e educação. Belo Horizonte: Autêntica, 2000.

9. LOURO, G. L. Gênero, sexualidade e educação: uma perspectiva pós-estruturalista. Rio de Janeiro: Vozes, 1997.

10. SILVA, T. T. (Org.). Identidade e diferença: perspectiva dos estudos culturais. Petrópolis: Vozes, 2000.

11. METZ, C. Film language: a semiotics of the cinema (Linguagem dos filmes: a semiótica do cinema). Chicago: The University of Chicago Press, 1991. p. 10
Essas realidades interpretadas são veiculadas de forma significativa pela indústria cultural, denunciada por Horkheimer e Adorno ${ }^{3}$ como aparato para homogeneização e padronização das consciências e visões de mundo. Entretanto, a mídia produz também construções de ordem mais complexa, capazes de redesenhar certezas, como é o caso de algumas produções cinematográficas. Tais trabalhos contribuem para processos de reflexão e crítica sobre a própria constituição de identidade do indivíduo, tanto para o homem quanto para a mulher.

Geada $^{4}$, Kellner ${ }^{5}$ e Kaplan ${ }^{6}$ são estudiosos que analisam as representações de violência, de classe social e de gênero em narrativas clássicas, principalmente do cinema hollywoodiano. Outros pesquisadores, como Henri Giroux ${ }^{7}$, trabalham com as articulações entre o cinema e a educação. No Brasil, o tema é estudado por Rosália Duarte ${ }^{8}$ e Guacira Lopes Louro ${ }^{9}$, abordando especificamente o uso do cinema para a discussão de questões de gênero e sexualidade.

\section{REPRESENTAÇÃO E IDENTIDADE}

Pelas narrativas, as mídias trabalham diretamente com a questão da identidade dos sujeitos, construindo personagens com os quais os sujeitos espectadores mantêm relações complexas, com investimentos afetivos que variam entre aceitação, rejeição ou repulsa.

Essas construções, entretanto, são freqüentemente naturalizadas. Fixam-se lugares para sujeitos entre pólos bem demarcados - homem/mulher, dona de casa/prostituta, heterossexual/homossexual -, representações binárias muito presentes nas narrativas televisivas e no clássico cinema hollywoodiano. Ser homem, dona de casa ou heterossexual corresponde ao que é natural, ou como aponta Silva ${ }^{10}$, citando Laclau, ao que é humano. Outros termos correspondem apenas a um acidente de percurso.

Assim, em contato direto com essas representações, identidades sociais são construídas, provocando nos sujeitos um certo grau tanto de subversão e resistência quanto de cumplicidade e submissão.

O cinema narrativo possibilita importantes processos de identificação. Desejos, prazeres, sentimentos conscientes e inconscientes fazem parte do repertório do espectador e de suas relações com o cinema. Elementos de realidade como o movimento, por exemplo, emprestam uma aura de verdade às construções produzidas pelos recursos narrativos cinematográficos.

Metz chama a atenção para processos inconscientes envolvidos na recepção cinematográfica. Enfatiza que, como espectadores/as, os sujeitos são desconectados do mundo real, tomando por realidade a ficção, "uma realidade que vem apenas de dentro de nós, a partir de projeções e identificações que estão misturadas à nossa percepção do filme"11. Esse investimento psicológico, aliado a outros processos de ordem cultural e intelectual, influencia a forma como interagimos com a mensagem. 
É por toda a complexidade e potencialidade do cinema que este se torna especialmente relevante para a formação docente. Ao se tornar objeto de reflexão e de análise por educadores, o cinema se mostra uma ferramenta capaz de alavancar transformações e ressignificações importantes a respeito de questões que concernem à condição humana e à constituição das subjetividade. Existe uma infinidade de imagens cinematográficas - algumas que reproduzem visões unilaterais e dicotômicas, outras que rompem com esses padrões - com potencial para dar suporte a ações educativas com os mais diversos fins e temáticas.

Não se trata apenas do valor do cinema como meio de acesso a informações ou de uma atitude crítica em relação a obras que reforcem diferentes hierarquias sociais, mas da descoberta do potencial educativo de certos filmes provocadores, no sentido de abalar certezas e visões dicotômicas estabelecidas, propiciando reflexões sobre outras possibilidades de ser e estar no mundo.

Aumount e Marie $^{12}$ ensinam que, para analisar uma obra, é preciso estar do lado do receptor, que não é o mesmo do cineasta, construindo uma interpretação plausível da mensagem e reconhecendo a influência do contexto formado pela cultura, pelas relações sociais e por contatos anteriores com o cinema. Estes mesmos autores defendem uma atitude que tenta romper com a dicotomia que se estabelece, geralmente, entre o estudo dos códigos e o conteúdo das mensagens, propondo uma análise que articule esses dois níveis da mensagem.

\section{PROCESSOS DE TRANSFORMAÇÃO E DESCONSTRUÇÃO POR MEIO DE IMAGENS}

Os filmes escolhidos para este exercício analítico foram produzidos nas décadas de 1960 e 1970, no Brasil e no exterior. São obras de diretores que, com criatividade, questionam os padrões vigentes e propõem novas formas de apreender o mundo.

Chuvas de Verão ${ }^{13}$, dirigido por Cacá Diegues, Julieta dos Espíritos ${ }^{14}$, obra de Federico Fellini, e Viver $a$ Vida ${ }^{15}$, trabalho de Jean Luc Godard: os três filmes têm reconhecido valor estético e cultural e, além disso, convidam o espectador a refletir a respeito dos significados culturalmente construídos de sexualidade e gênero. Nessas obras, os desejos, a imaginação e os sonhos têm lugar privilegiado.

Chuvas de Verão mostra transformações significativas na vida de um funcionário público aposentado, Afonso, quando, durante um verão suburbano carioca, se envolve em situações conflitantes que o despertam para uma nova relação amorosa com Isaura, sua vizinha. Os protagonistas são pessoas idosas, passando por mudanças profundas em suas vidas e vivendo um momento delicado em que procuram abrir-se para o mundo. A história trabalha com projeções de medos e sonhos da velhice, assim como com os tabus presentes no cotidiano do espectador.

Dessa obra sensível, merece destaque a seqüência em que Afonso e Isaura, velhos e desiludidos, se encontram. Os elementos estéticos dados a essa seqüência a tornam, ao mesmo tempo, educativa e provocadora. Afonso está no
12. AUMONT, J.; MARIE, M. L'analyse des filmes (A análise dos filmes). 2. ed. Paris: Nathan, 1999.

13. CHUVAS de Verão. Direção: Cacá Diegues. Brasil, 1977, 86 min.

14. JULIETA dos Espíritos (Giulietta degli Spiriti). Direção: Federico Fellini. Itália, 1965, 148 min.

15. VIVER a vida (Vivre sa vie). Direção: Jean Luc Godard. França, 1962, $45 \mathrm{~min}$. 
quarto, abatido, sentado à beira da cama, pedindo que Deus o leve, enquanto bate ritmicamente no peito. A campainha toca, e ele abre a porta para Isaura, por quem, há tempos, sente-se atraído. Ela entra timidamente. $\mathrm{Na}$ sala, os dois conversam, pouco à vontade. Há certa imprecisão e aleatoriedade no enquadramento da cena. A técnica de filmagem reitera o estado de espírito dos dois personagens que, pouco a pouco, entre um gole e outro de cerveja, vão se descontraindo. Interessante notar que, como em outros filmes brasileiros, a cerveja aparece como elemento cultural lícito para a aproximação entre pessoas.

Isaura e Afonso falam de sua vida e do passado. Em um envolvimento crescente, o casal dança. Entretanto, ao ser beijada, Isaura se retrai. A seqüência seguinte é no quarto, onde Isaura, ainda cheia de medo e pudor, finalmente cede ao desejo, e os dois fazem amor. O clima é constituído por palavras e imagens poéticas, complementado pela música de fundo. A câmera se demora nos corpos entregues e na expressão corporal dos personagens.

$\mathrm{O}$ espectador presencia imagens que, em um primeiro momento, podem

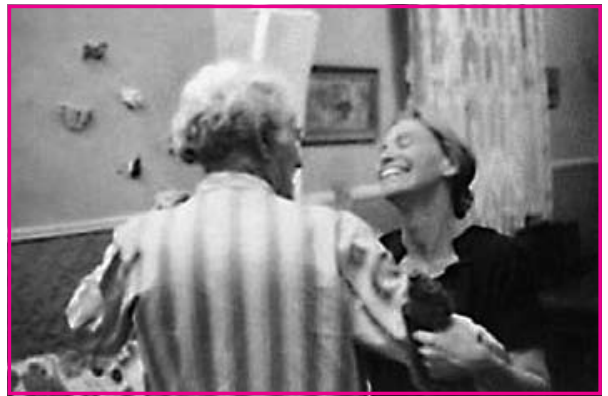

Jofre Soares e Míriam Pires em Chuvas de Verão. provocar estranhamento por não serem familiares. $\mathrm{O}$ velho também ama. A mulher idosa é bela aos olhos do amante. Os corpos desnudos e enrugados são oferecidos ao observador pelo olhar prolongado da câmera em planos, em detalhes de partes dos corpos e na tomada geral.

"Nós não temos mais idade para estas coisas, seu Afonso..." O significado deste enunciado de Isaura pode ser aceito por muitos, por aqueles que se sujeitam aos discursos construídos que estabelecem, de forma categórica, as posições e normas sociais da velhice, da mulher, do homem.

Mas a imagem não se esvanece. Instiga a um diálogo difícil, propondo um exercício ao espectador, o de despertar a consciência para as prescrições e regras internalizadas a partir dos discursos construídos pelos textos e pelo enquadramento minucioso das ações e dos corpos. Evidencia-se o condicionamento provocado pela cegueira em relação a questões essenciais da existência humana - ao amor e às relações afetivas e amorosas. Por essas ressignificações, pouco a pouco, a imagem vai-se transformando, os corpos tornam-se belos porque exibem ao espectador os elementos essenciais da plenitude da vida, propostos pelo relacionamento entre Isaura e Afonso.

Representações sociais entranhadas e sedimentadas - que associam o amor ao belo e ao jovem e a velhice, ao esmorecer da vida e à ausência de sexualidade - são desconstruídas pela recombinação sígnica concebida por trabalhos com tal profundidade.

Exercícios de leitura como esses possibilitam o entendimento da natureza cultural na pós-modernidade. 4. ed. Rio de Janeiro: DP\&A Editora, 2000.

e da constituição de nossa subjetividade. Despertam a consciência em relação à forma como o ser humano é culturalmente representado. Segundo Hall ${ }^{16}$, o 
homem é sempre interpelado pelos sistemas culturais que o rodeiam e pelas relações sociais que estabelece. Isso impacta, inevitavelmente, na formação das identidades.

A partir de Chuvas de Verão é possível entender a complexidade da sexualidade, não como algo que diz respeito a um único tipo de experiência, mas como um processo complexo, ligado a condições históricas e aos mais diversos

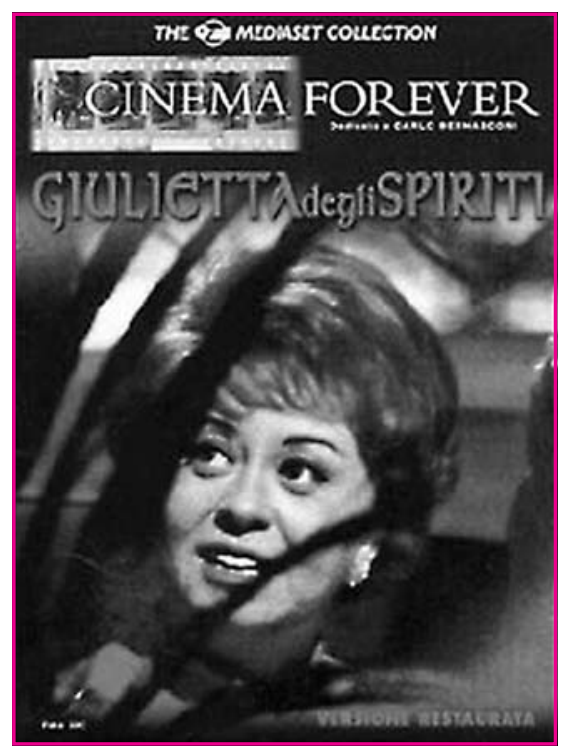

Giulietta Masina, esposa de Fellini, em Julieta dos Espíritos.

\section{discursos.}

Em Julieta dos Espíritos, filme dirigido por Federico Fellini, Julieta é a personagem central do filme, uma dona de casa italiana com uma sexualidade conflituosa que mistura repressão e liberação, fantasias e memórias. O/A espectador/a é levado/a a acompanhar sua abertura para a vida, a partir de um acerto de contas com os medos e traumas da infância.

Esse movimento tem início quando seu casamento, até então considerado exemplar, é abalado por uma traição do marido. Julieta rompe, assim, com os limites impostos pela sua bela casa, deixa os afazeres domésticos para descobrir um mundo mais complexo que, como reflexo de seu próprio ser feminino, é cheio de contradições e desejos.

Nessa aventura, defronta-se com corpos livres, cheios de desejo, que abalam seu passado repressor, ao qual insistentemente recorre. Ela aproveita para um acerto de contas com a mãe majestosa e para um diálogo com o avô morto, que havia deixado marcas indeléveis em sua vida.

Duas seqüências do filme servem como metáforas para as transformações de identidade da protagonista: de mulher tolhida por antigos "fantasmas" para um ser aberto e em busca de uma nova identificação. A primeira mostra Julieta adulta, observando Julieta criança, em uma peça infantil, quando esta representava Joana d'Arc, no momento em que é levada à fogueira. $\mathrm{O}$ avô interrompe a cena furioso, por colocarem a criança naquela situação. A segunda seqüência traz Julieta adulta, no quarto, quando lhe aparece a mãe, aconselhando-a a não abrir a porta, símbolo de seu passado repressor. A protagonista, entretanto, desobedece, abre a porta e depara-se com a menina Julieta nas amarras do fogo. Ela a liberta, selando essa atitude com um abraço afetuoso.

O mergulho no mundo fantasioso da liberdade, do desejo e da repulsa à repressão da sexualidade também faz parte desse alargamento do mundo da personagem. Assim, Julieta é exibida de forma complexa, convivendo de forma dialética com sentimentos de afeição e raiva, medo e coragem, preconceito e admiração. Seu self torna-se, no decorrer da narrativa, como diria Hall ${ }^{17}$, uma “celebração móvel”, formada e transformada continuamente em relação às representações e interpelações propostas pelos sistemas culturais vigentes. 
Interessante ressaltar que, tanto em Chuvas de Verão quanto em Julieta dos Espiritos, particularmente nas seqüências destacadas, o/a espectador/a é levado/a a se defrontar com a complexidade e a incompletude das identidades, com as transformações e ampliações da consciência em relação aos papéis atribuídos à mulher e ao idoso na sociedade.

Viver a Vida, filme experimental dirigido por Godard, trata do processo pelo qual Ana, uma parisiense, se torna prostituta. O filme é formado por 12 quadros independentes, mas relacionados tematicamente, que compõem uma crítica à situação de opressão da mulher.

No primeiro quadro já se evidencia o caráter experimental do filme, quando Ana aparece com o ex-marido, de quem se divorciara há pouco. Ambos estão de costas e em silêncio, silêncio que também é personagem do filme e recurso expressivo de Godard.

Divorciada, Ana busca um trabalho para se manter: modelo, atriz, vendedo-

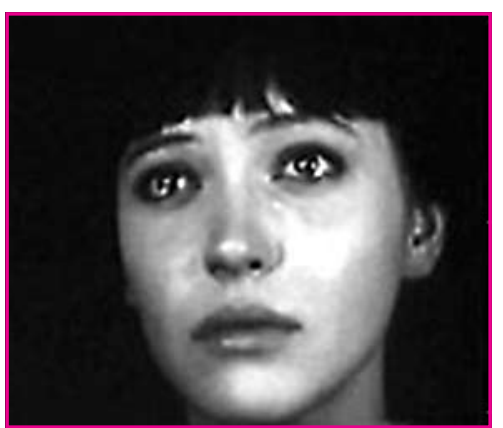

Anna Karina em Viver a Vida. ra. Frustrada em suas inúmeras tentativas, acaba nas mãos de um cafetão, Raul, que a explora. Já prostituta, apaixona-se, mas não consegue mais modificar sua vida. $\mathrm{O}$ quadro que apresenta a primeira vez em que Ana vende seu corpo, suscita questões importantes acerca da prostituição - ela caminha lentamente pela rua, quando um homem bem vestido a aborda. Ambos se dirigem a um quarto de hotel, onde acontecem a barganha, o pagamento e a "posse".

A câmara não tem pressa. Convida o espectador a pensar, estabelecendo um diálogo com sua subjetividade e suas experiências, preenchendo os hiatos do discurso narrativo. Transforma-o/a em cúmplice dos personagens, fazendo-o/a compartilhar de suas emoções. Quando a câmara faz um demorado close do rosto da reflexiva Ana, empurra o/a espectador/a para um mergulho em si mesmo/a, em sua própria vida. A imagem se torna o espelho que reflete simultaneamente personagem e espectador.

Ana não tem as características nem os signos geralmente associados à prostituição. Suas roupas, expressão corporal, fala e hábitos intelectuais desmentem o modelo atribuído à prostituição, marcado quase sempre pela ignorância, pelo gesto exagerado, por comportamentos escandalosos. O que significa prostituirse? Em que medida as relações de gênero estabelecidas e aceitas como naturais pela sociedade não acarretam diferentes tipos de prostituição?

Filmes como esse não terminam quando se acendem as luzes, pois colocam o/a espectador/a em contato com os conflitos tratados pela narrativa que, por sua vez, não apresenta soluções, apenas questionamentos.

As representações de sexualidade e as relações de gênero resgatadas por esses filmes, sem dúvida, trazem para o debate os modelos de comportamento tradicionalmente aceitos na sociedade, nos quais as mulheres ocupam um lugar específico, marcado pelas condições concretas da existência. 


\section{O CINEMA E A FORMAÇÃO DOCENTE}

Conhecer essas diferentes construções ajuda a romper com a naturalização que envolve as questões de gênero. É relevante aqui a postura defendida pelos/as autores/as contemporâneos que colocam em foco o que é essencial no sujeito, percebido por suas formas de ver o mundo, em contraste ou em conformidade com os papéis que cumpre na sociedade.

Por esse viés, o/a docente tem possibilidade de elaborar uma crítica à polarização que caracteriza os diferentes papéis que o sujeito assume na cultura. Papéis esses que, certamente, influem no currículo oculto escolar. Nesse sentido, torna-se essencial considerar como as conotações de valor são introjetadas sem maiores reflexões, em práticas e discursos sobre o comportamento esperado de meninos e meninas, jovens e idosos, do bom e do mau aluno.

A percepção do sujeito construído e transformado continuamente pela linguagem se contrapõe à do sujeito centrado e autônomo, que prevalece dentro do projeto da modernidade. O cinema, ao apresentar essas diferentes formas de retratar o ser humano, contribui para o entendimento de questões do inconsciente que não se enquadram na racionalidade pretendida pelo pensamento moderno.

Eixos importantes perpassam forma e conteúdo dos filmes estudados, reservando espaço privilegiado para os desejos, a imaginação e os sonhos. O cotidiano, onde se desenvolvem as vidas reais e ficcionais, é o cenário de angústias, de decepções e, ao mesmo tempo, de liberdade e desejos satisfeitos. No mundo atual, em que os olhares se mostram particularmente viciados, o contato com a integridade do ser é uma das alternativas para se despojar do artificialismo. Isto, o cinema torna possível em algumas de suas obras mais significativas.

$\mathrm{O} / \mathrm{A}$ docente, ao interagir com imagens e interpretar os signos utilizados na construção narrativa, passa a entender os mecanismos sociais e as metáforas que influenciam a construção do olhar do ser humano sobre si mesmo e sobre o outro. Esse processo torna possível tanto a identificação quanto o estranhamento. Daí o rompimento com certos preconceitos e naturalizações.

\section{NOVOS SENTIDOS PARA AS VELHAS QUESTÕES}

Rupturas, novas dimensões e novos olhares são processos educativos no seu significado mais genuíno. É no sentido colocado por Pasolini, e endossado por $\mathrm{Geada}^{18}$, que se entende o pedagógico no cinema, atribuindo à idéia de provocação lugar central: provocar não só com o propósito estrito de desafiar as pessoas, como também de instigar novos questionamentos ou produzir novos pontos de vista para velhas questões.

Nos filmes analisados, a natureza contraditória das subjetividades contrasta com as tradicionais oposições binárias que prevalecem nas representações midiáticas. Os mecanismos usados pelas narrativas tradicionais são omissos, diante dos paradoxos dos personagens. Em contrapartida, nas obras aqui tratadas, o/a

18. GEADA, E. O poder do cinema, op. cit. 
espectador/a é convidado/a para uma auto-reflexão à medida que se envolve na teia de contradições apresentada. Sexualidade pode ser tema correlato tanto à liberação quanto à subjugação.

Elementos contidos em algumas narrativas podem interrogar, complementar e rever os paradigmas estabelecidos nas relações de gênero e sexualidade. $O$ educativo é construído por meio do diálogo e de uma postura interpretativa ativa e atuante, ante a obra que, por sua vez, remete o/a espectador/a à identificação com um ou outro personagem, às representações do amor e da sexualidade e à análise dos diferentes códigos que constroem uma cena. Assim, uma relação dialética de aproximação e distanciamento - desencadeadora de um estado de prontidão crítica - se estabelece a partir do filme. Há uma desconstrução da aparente naturalidade diante da problematização das experiências e da subjetividade.

Dessa forma, a inclusão de narrativas cinematográficas e literárias em processos de formação docente pode contribuir para que se respeitem as implicações subjetivas das pessoas. Esse é o desafio que Deacon e Parker ${ }^{19}$ identificam como objeto das investigações de Foucault - quando o filósofo se refere às possibilidades de ação do sujeito dentro das redes de poder em que está inserido: "Nossa tarefa poderia ser não descobrir o que somos, mas recusar o que somos... imaginar e construir o que poderíamos ser... para promover novas formas de subjetividade".

Resumo: $O$ artigo aponta para o potencial de algumas obras cinematográficas como mediadoras na desnaturalização de questões de sexualidade e gênero. Elabora, ainda, uma reflexão sobre a pertinência e a contribuição deste tema para a formação docente. Com base nos estudos culturais, a análise destaca a importância do cinema para a construção das identidades culturais dos indivíduos. O exame de seqüências de três produções cinematográficas das décadas de 1960 e 1970 - Chuvas de Verão, de Cacá Diegues, Julieta dos Espíritos, de Federico Fellini, e Viver a vida, de Jean Luc Godard - colabora para a desconstrução de estereótipos e resgata a complexidade das questões de gênero e sexualidade. Como objeto de reflexão e análise por educadores, o cinema se mostra uma ferramenta capaz de alavancar transformações e ressignificações sobre a vida e os papéis sociais.

Palavras-chave: gênero e sexualidade, cinema e educação, formação docente, subjetividade, identidades culturais.
Abstract: The article indicates the potential of some motion pictures as mediators in the denaturalization of sexuality and gender issues. It also offers a reflection on the pertinence and contribution of this matter for the teachers' education. Based in the Cultural Studies, this analysis highlights the importance of cinema for building the individual cultural identity. The examination of sequences of three cinematographic productions from the Sixties and Seventies - Chuvas de Verão, by Cacá Diegues; Julieta dos Espíritos, by Federico Fellini; and Vivre sa Vie, by Jean Luc Godard - supports the deconstruction of stereotypes and redeem the complexity of the sexuality and gender issues. As object of reflection and analysis by teachers, cinema shows to be a tool capable of leveraging change and meaning shifts of life and social roles.

Keywords: gender and sexuality, cinema and education, teachers' education, subjectivity, cultural identities.
B. Educação como sujeição e como recusa. In SILVA, T. T. (Org.). O sujeito da educação: estudos foucaultianos. Petrópolis: Vozes, 1994 